\title{
A montanha e os caminhos: Sérgio Buarque de Holanda entre Rio de Janeiro e São Paulo
}

\author{
Mountains and byways: Sérgio Buarque de \\ Holanda between Rio de Janeiro and São Paulo
}

Robert Wegner*

\section{Resumo}

O objetivo do artigo é investigar a gestação de um projeto intelectual de Sérgio Buarque de Holanda: estudar as bandeiras, as monções e seus desdobramentos. Nesse sentido, analiso a trajetória do autor durante o primeiro governo Vargas, especialmente o momento em que lança Raízes do Brasil, em 1936, e o estabelecimento do Estado Novo no ano seguinte. Argumento que é nesse contexto que Sérgio Buarque passa a estudar a história da sociedade paulista, pensando-a como uma alternativa para a modernização da tradição ibérica.

Palavras-chave: cordialidade; fronteira; mentalidade capitalista.

\begin{abstract}
This article investigates the development of an intellectual project by Sérgio Buarque de Holanda: to study the expeditions by land and river into the inland parts of Brazil, and their aftermath. I analyze the author's trajectory during the first Vargas government, especially when he publishes Raizes do Brasil [Roots of Brazil] in 1936, and the establishment of the Estado Novo dictatorship the following year. I argue that it was in this context that Sérgio Buarque started to study the history of São Paulo society, viewing it as an alternative to traditional Iberian-style modernization. Keywords: cordiality; frontier; capitalist mentality.
\end{abstract}

Sérgio Buarque de Holanda (1902-1982) era paulista e, em 1921, após a aposentadoria do pai, mudou-se para o Rio de Janeiro. A agitada década de 1920 foi vivenciada por ele nessa cidade em uma intensa militância no movimento modernista, com o interregno de alguns meses de 1927 passados em Cachoeiro do Itapemirim, no Espírito Santo, após a publicação, em outubro do ano anterior, de seu polêmico artigo "O lado oposto e outros lados". Em meados de 1929 vai ser correspondente de O Jornal na Alemanha. Este artigo

\footnotetext{
* Pesquisador, Casa de Oswaldo Cruz; Programa de Pós-Graduação em História das Ciências e da Saúde/Fiocruz; Departamento de Ciências Sociais, PUC-Rio. Rio de Janeiro, RJ, Brasil. robertwegner coc@gmail.com ${ }^{1}$
} 
dedica-se ao período que se inicia com o retorno de Sérgio Buarque ao Brasil, quando se estabelece novamente no Rio de Janeiro, e se estende até sua mudança para São Paulo, em 1946, e a publicação de "Índios e mamelucos na expansão paulista” nos Anais do Museu Paulista, em 1949. Portanto, seu contexto são os anos do primeiro governo Vargas e os que se seguiram ao fim do Estado Novo.

Meu primeiro objetivo é o de analisar o significado de Raízes do Brasil a partir da indagação, inspirada em Quentin Skinner (1969, p.45-46), sobre o que Sérgio Buarque pretendia fazer ao lançar seu ensaio no contexto específico de 1936. Em segundo lugar, levando em consideração a recepção do livro, o estabelecimento do Estado Novo em 1937 e o lançamento do livro de Almir de Andrade, Força, cultura e liberdade, em 1940, investigar a gestação de um novo projeto intelectual de Sérgio Buarque, o de estudar as bandeiras, as monções e seus desdobramentos. Esse projeto o acompanhará daí por diante, mas no presente artigo dedico-me apenas aos seus delineamentos iniciais e ao seu significado político. Por fim, sustento que, se é correto afirmar que Monções (1945) representa o início da carreira de Sérgio Buarque como historiador, não significa o abandono da intervenção no espaço público, característica do ensaísta. Ao lado disso, procuro argumentar que, durante o Estado Novo, o Rio de Janeiro passou a simbolizar para ele o peso do legado ibérico e sua consubstanciação em um Estado autoritário, enquanto São Paulo foi cada vez mais representando um caminho de modernização da tradição ibérica e de uma sociedade mais individualista e democrática.

\section{VERÃo NO Rio DE JANEIRO}

Ainda na Alemanha, Sérgio Buarque escreve um artigo entusiasmado com a eleição de Júlio Prestes para presidente, ocorrida em $1^{\circ}$ de março de 1930. Publicado em uma revista que visava incrementar as relações comerciais entre Brasil e Alemanha, o artigo faz um balanço da gestão do político como governador de São Paulo, ressaltando os avanços do Estado na economia, na saúde e na ciência, e prevê que sua presidência traria a perspectiva de expandir esse sucesso: "seu brilhante passado justifica a esperança de que seu governo seja um dos mais felizes e frutuosos para o Brasil” (Holanda, 2011, p.42). Júlio Prestes não assumiria em novembro de 1930, como previsto, e, meses depois da ascensão de Getúlio Vargas ao poder, Sérgio Buarque voltaria ao Brasil, em janeiro de 1931. Segundo confidenciou a um amigo, o retorno se devia ao fato de sua namorada alemã ter engravidado. Pouco depois, Múcio Leão escreve a 
um amigo em comum "que isso de ter amantes na Alemanha é para uma moça coisa inteiramente grave. O resultado da aventura do Sergio foi que ele teve de sair precipitadamente de Berlim, com um severo processo em cima da corcova" (Leão, 1931).

Como registraria Maria Amélia Buarque de Holanda, "chegando ao Rio, retomou o jornalismo e o trabalho em agências telegráficas: Havas, Agência Brasileira, United Press" (Holanda, 2006, p.433). Assim, Sérgio Buarque de Holanda voltou a trabalhar como tradutor de telegramas, "acolhido pelo antigo chefe, Alberto Ramos, na Agência Havas, que, com a Reuters, predominaram no noticiário internacional da imprensa brasileira durante todo o Império e a Primeira República” (Barbosa, 1988, p.46). No conturbado ano de 1932, ele permanece no Rio de Janeiro, mas não deixa de se manifestar a favor de São Paulo durante a Revolução Constitucionalista. Como registra ainda sua esposa, “em 32, Sérgio estava no Rio na turma dos boatos e da torcida revolucionária. Acabou preso, soltando vivas a São Paulo, em pleno Mangue, no meio de um grupo de onde constavam Octavio Tarquinio de Sousa, Tristão da Cunha, Ribeiro Couto, todos comboiando o escritor francês Luc Durtain" (Holanda, 2006, p.433).

Isso não significa que Sérgio estivesse desconfortável no Rio de Janeiro, cidade que, nos anos seguintes, com a prefeitura de Pedro Ernesto Batista (1931-1936), ganharia vivacidade política e cultural impressionantes. Trabalhando como tradutor e jornalista e chegando a chefiar a sucursal do jornal Folha de Minas na cidade (Barbosa, 1988, p.49), frequenta com os amigos seus bares e espaços de sociabilidade. Em 1935, a cidade ganhava a Universidade do Distrito Federal (UDF), projeto inovador de Anísio Teixeira, diretor do Departamento de Educação desde 1931, que trazia 16 professores estrangeiros e enfatizava a associação entre ensino e pesquisa. Sob a reitoria de Afonso Pena Júnior, Prudente de Moraes, neto - velho amigo dos tempos do modernismo e da direção compartilhada da revista Estética, em 1924 e 1925 - dirige a Faculdade de Filosofia e Letras e, nessa condição, convida Sérgio a ingressar na Universidade em 1936, onde tem a possibilidade de ser assistente de Henri Hauser na cadeira de História Moderna e Econômica, e de Henri Tronchon, na cadeira de Literatura Comparada (Holanda, 1979, p.14; Holanda, 2006, p.434). Embora curta, essa experiência universitária foi importante para sua formação.

Sérgio Buarque conta que retornara da Alemanha em janeiro de 1931 com um "calhamaço de suas 400 páginas" relativo ao livro que vinha acalentando desde antes de sua viagem, que "deveria chamar-se Teoria da América conforme 
comuniquei então a Prudente, meu comparsa constante em todos os prélios intelectuais" (Holanda, 1979, p.30). A partir dessas páginas ele produziu o artigo "Corpo e alma do Brasil: ensaio de psicologia social", publicado em março de 1935 na revista Espelho. No ano seguinte, viria à luz Raízes do Brasil. Como é notória a presença de Max Weber em Raízes do Brasil, costumamos pensá-lo como pertencente à "fase alemã" da "história mental" de Sérgio Buarque, na expressão de Antonio Candido (1988, p.9-10). Não se deve esquecer, no entanto, como escreve Luiz Feldman, que "muito de Raízes do Brasil está no diálogo com autores brasileiros", como Gilberto Freyre, Alberto Torres e Oliveira Vianna, ou ainda "outros tantos quase sempre esquecidos" (Feldman, 2016, p.34). Complementarmente, vale refletir que o ensaio é fruto de um contexto universitário, pois o próprio autor grifou a importância de sua convivência com Henri Hauser, na UDF, para a sua composição (Holanda, 1979, p.14). Somos inclinados a pensar que Raízes do Brasil seria produto de uma experiência pré-universitária, mas podemos supor uma afinidade entre ensaio e a vida universitária da UDF. Sem pretender explorar esse ponto, vale ao menos recordar que a Universidade contou também com a colaboração de Gilberto Freyre, até então muito próximo a Sérgio e que publicara Casa-grande \& senzala em 1933, além de, já atuando como professor de Sociologia, publicar seu segundo ensaio, Sobrados e mucambos, em 1936, ano de lançamento de Raízes do Brasil, apresentado por Freyre. Quando Raízes do Brasil foi lançado, as resenhas publicadas em jornal foram bastante semelhantes.

Como expõe Luiz Feldman, "os elogios deviam-se predominantemente ao talento com que Sérgio Buarque captara algo próprio da psicologia do homem brasileiro". Por sua vez, "as dificuldades na leitura vinham da avaliação de que, lamentavelmente, o livro terminava sem uma conclusão nítida”. Resume Feldman: "ao admirável diagnóstico parecia ter faltado o complemento de uma visão política bem articulada” (Feldman, 2016, p.185-186). Nos últimos 30 anos, muito se discutiu sobre a interpretação levada a cabo em Raízes do Brasil e a posição política sustentada por Sérgio Buarque de Holanda. Desde o momento em que os estudiosos redescobriram a primeira edição do livro e esmiuçaram as mudanças empreendidas a partir da versão de 1948, deixou de ser satisfatória a leitura de Antonio Candido de que Sérgio teria lançado um manifesto democrático e que o autor era um representante do radicalismo de classe média. Conforme observa Luiz Feldman, os textos de Candido

moldam, há gerações, o entendimento sobre a obra [Raízes do Brasil]. No entanto, contribuem sistematicamente para um discurso sobre o pioneirismo e a coe- 
rência da obra e do autor - no que respeita à edição princeps do livro, bem entendido - que dificulta o estudo e o debate do significado de Raízes do Brasil no ano em que se tornou mera convenção situar seu aparecimento: 1936. (Feldman, 2016, p.22)

Talvez não seja muito esquemático dizer que a redescoberta da primeira edição - cuja versão volta a circular em 2016, por meio da edição comemorativa dos 80 anos de Raízes do Brasil - reaproximou as interpretações recentes das primeiras resenhas do livro. Desse modo, por exemplo, Leopoldo Waizbort argumenta que na primeira edição Sérgio Buarque é tributário de correntes irracionalistas e do pensamento conservador, o que tornava mais claro, na versão de 1936, a busca pela personalidade social da nação. Ao passo que, compartilhando dessa ambiência, as resenhas da época enalteciam essa intenção e apontavam o sucesso alcançado, Waizbort articula seu argumento em tom crítico. Por sua vez, se os contemporâneos de Sérgio apontam a falta de um programa político, Waizbort sugere que o personalismo marcante da psicologia do povo apontava para uma solução política oligárquica e um Estado que passava longe da organização da Primeira República e também do início do governo Vargas, remetendo muito mais a "uma espécie de nostalgia do Império, no reconhecimento de que aquela situação ou cristalização histórica era mais afim à alma nacional ... Sérgio Buarque desenvolve o argumento de que o Império havia concretizado um Estado forte, de que carecemos, sem cair no despotismo que recusa" (Waizbort, 2011, p.44). ${ }^{2}$ Como o autor sugere, Sérgio trabalha com a ideia de crise, em um descompasso entre as mudanças das estruturas sociais de caráter democratizante e a psicologia do brasileiro, inadequada a essas transformações.

Já em A queda do aventureiro, Pedro Meira Monteiro empreendeu uma leitura em que procura brechas na psicologia do brasileiro que apontem para uma compatibilidade com a democracia. No capítulo sobre "o homem cordial”, Monteiro valorizou as passagens em que Sérgio se refere às modernas teorias da educação, que descentravam o papel da família e, segundo as quais, "a criança deve ser preparada para desobedecer nos pontos em que sejam falíveis as previsões dos pais” (Knight Dunlap, apud Holanda, 1936, p.97). Monteiro sugere que, em Raízes, a discussão sobre educação não é realizada com o mero fim de apresentar a oposição entre a centralidade da família nas sociedades tradicionais e a da escola nas sociedades modernas, mas vinha demonstrar que, para Sérgio, era importante "assegurar ... a autonomia do indivíduo contra os princípios da tradição e da autoridade absoluta da figura 
paterna" (Monteiro, 1999, p.183). Para o intérprete, importa mais sugerir que Sérgio "distancia-se bastante de Gilberto Freyre na apreciação dos valores patriarcais” (Monteiro, 1999, p.181), do que a discussão sobre educação em si mesma. Mesmo porque o ensaísta não era, por exemplo, um entusiasta das campanhas de erradicação do analfabetismo, pois em Raízes escrevia: "imagine-se como ficariam desapontados ou indignados esses crédulos predicadores do progresso, se lhes fossem dizer que essa alfabetização em massa, que propugnam como o nec plus ultra do adiantamento e da civilização não é, talvez, uma coisa absolutamente essencial e mesmo que não é, em si, um benefício sem par" (Holanda, 1936, p.129-130).

Ainda assim, tomando um caminho alternativo, a discussão sobre educação presente no capítulo 5 de Raízes pode nos remeter àquela que vinha sendo efetivamente realizada no Rio de Janeiro do primeiro quinquênio da década de 1930 e nos conduzir à efervescência da cidade no período. Considerando os autores citados, Sérgio está familiarizado com o movimento da Escola Nova e acompanha o processo de democratização das escolas no Distrito Federal. Como afirma Jerry Dávila, nesse momento, “o sistema escolar do Rio era o mais próximo de uma educação pública universal que o Brasil possuía, um feito notável dado o explosivo crescimento da cidade ao longo do século". Segundo seus dados, "dois terços das crianças da cidade entre sete e doze anos frequentavam a escola em 1935. Os gastos per capita com educação pública eram mais do que o dobro dos de São Paulo e quase quatro vezes a média nacional”. Ainda nas palavras de Dávila, "à medida que imigrantes e migrantes se desligavam das redes tradicionais de relações patrono/cliente que regulavam anteriormente as relações sociais, a escola se tornava um patrono virtual ao alocar serviços sociais, projetar critérios para a cidadania e integrar a crescente população ao tecido social” (Dávila, 2006, p.124-126).

Somando-se a isso, deve-se ressaltar que as concepções do principal mentor da democratização da educação no Distrito Federal, Anísio Teixeira, correspondiam às daqueles sociólogos citados por Sérgio Buarque. Por assim dizer, Teixeira assinaria embaixo da síntese presente em Raízes do Brasil, pela qual "segundo os pedagogos e os psicólogos mais venerados de nossos dias, a educação familiar deve ser apenas uma espécie de propedêutica da vida em sociedade, fora da família. E se bem considerarmos as teorias modernas, veremos que elas tendem, cada vez mais, a destacar o indivíduo da comunidade doméstica, a 'libertá-lo’ das virtudes familiares" (Holanda, 1936, p.96).

Sem estabelecer uma ligação entre o sistema escolar no Rio de Janeiro e o decréscimo do predomínio da família na educação - com o consequente 
estancamento da fonte da "cordialidade" e do predomínio dos laços afetivos -, vale tomá-lo como um sintoma da dinâmica cultural da cidade e um termômetro dos projetos de nação para o país como um todo. Assim, seguindo Marly Silva da Motta, a educação representada por Anísio Teixeira fazia parte de um projeto mais amplo de Pedro Ernesto, em que "o ingresso dos 'pobres', dos 'favelados', no mundo formal da cidadania política era o principal desafio a ser enfrentado pelo prefeito". Nesse contexto, a cidade representava a "vitrine" do projeto nacional, devendo "não só reafirmar sua posição de maior centro cultural e educacional do país, como ostentar um eleitorado consciente e atuante". Por isso, ao lado da sua "aposta na via eleitoral-partidária, isto é, na cidadania política” (Motta, 2001, p.54), Pedro Ernesto lutava pela conquista da autonomia do Distrito Federal, tendo criado o Partido Autonomista do Distrito Federal.

\section{RAÍZES DO BRASIL COMO UM “LANCE” DEMOCRÁTICO}

Tendo em mente a efervescência cultural da cidade, gostaria de pensar o lançamento de Raízes do Brasil, em 1936, indagando se, desde então, o autor faz, realmente, uma opção pela democracia. Para Sérgio, 1936 é um ano feliz e portador de esperanças para o Brasil. Além de seu livro inaugurar a coleção Documentos Brasileiros, da editora José Olympio, ele se casa com Maria Amélia Cesário Alvim e vai "morar em uma casa na Praia do Leme, com uma varanda nos dois andares, que davam para o mar" (Graham, 2009, p.199), e se torna professor da Universidade do Distrito Federal (UDF). Em suma, vive de forma intensa a efervescência política, cultural e intelectual de um Rio de Janeiro dos anos constitucionais do governo Vargas - embora com perseguição aos comunistas e sucessivos estados de sítio, que vinham desde o fim de 1935.

Sobre Raízes do Brasil, os estudiosos têm apontado a importância de interpretá-lo como um ensaio. Assim, sua forma é tão importante quanto o conteúdo. Nesse sentido, sugiro que a ausência de fecho programático, característica tão notada pelos primeiros críticos, faz parte de uma atitude ensaística e configura um posicionamento político de Sérgio Buarque. Não afirmar como o Estado deve se organizar é se dirigir para o espaço público, para os cidadãos que ousam pensar o país e a si mesmos, e não para os intelectuais que se viam como participantes do processo de state-building. É como se, com o lançamento de Raízes do Brasil, Sérgio Buarque estivesse fazendo uma aposta dirigida ao espaço público e ao seu fortalecimento. Um "lance" dirigido aos debates nos cafés, nos bares, nas organizações civis. E aqui vale salientar mais um detalhe do caráter ensaístico do livro: ao descrever o caráter nacional e dizer aos seus 
contemporâneos que eram "homens cordiais", Sérgio se dirigia a todos e a cada um. Era, ao mesmo tempo, uma constatação e uma provocação. Ao lembrar que a sociedade brasileira vinha passando por uma revolução silenciosa, ao menos desde 1888, Sérgio proferia que a identidade do brasileiro encontrava-se em processo de reconstrução. Nesse sentido, ele executou um "lance" com o qual procurava modificar aquilo mesmo que descrevia (Pocock, 2003, p.39). Portanto, fazia todo sentido discutir e pensar a cordialidade nos espaços públicos, pois a forma do Estado antes teria a ver com o que os brasileiros, aos menos os das classes médias urbanas, desejassem fazer daquilo que eram.

Se não optava univocamente pela democracia e, ao mesmo tempo, "prudente", no entender de Feldman, "não descartava de todo a possibilidade futura de alguma solução democrática” (Feldman, 2016, p.167), Sérgio, deliberadamente, tateava várias possibilidades sem optar por nenhuma de forma definitiva. Contudo, levando-se em consideração a sua forma - e, no ensaio, forma é também conteúdo e uma modalidade de inscrição no mundo público -, Sérgio se definia por uma saída democrática. A organização política do Brasil poderia se dar de diversas maneiras; qual seria, ainda não estava clara, mas todas passariam pelo cultivo e ampliação do espaço público, em que os cidadãos pudessem participar dos debates sobre os rumos da nação, e isso significava que todas as saídas passavam necessariamente pela democracia.

Tudo isso nos remete novamente ao diálogo com Antonio Candido. As críticas recentes, como as de Waizbort (2011) e Feldman (2016), reconhecem que ele fez uma leitura extremamente rica de Raízes, mas tornou-a enviesada, ao atribuir à primeira edição passagens que apareceriam apenas nas versões posteriores, o que lhe permitiu imputar a Sérgio Buarque uma atitude democrática já na edição original. De fato, é preciso rever isso e admitir, com Feldman, que "a democracia nem sempre foi o ponto de chegada da discussão de Raízes do Brasil” (Feldman, 2016, p.161). Porém, se levarmos em consideração o caráter ensaístico de Raízes e a sua forma, talvez seja possível resgatar um pouco a ideia de que sua publicação tenha sido um "lance" democrático e que, ao menos nesse sentido, Antonio Candido tenha razão ao afirmar que Sérgio Buarque participa de um "radicalismo de classe média" (Candido, 1990, p.4 e 18).

\section{RIO DE JANEIRO NUBLADO}

No ano seguinte ao lançamento de Raízes do Brasil é instaurado o Estado Novo. O Congresso é fechado, são abolidas as eleições e os estados de sítio passageiros tornam-se ditadura. $\mathrm{O}$ espaço público se estreita, os lugares de livre 
debate, ruas, bares, se veem sob ameaça. O Rio de Janeiro, que vinha se autonomizando como cidade nos primeiros anos da década de 1930, durante a gestão do prefeito Pedro Ernesto, torna-se a capital do Estado Novo (Motta, 2001, cap. 1). A UDF é fechada em 1939 e, a partir de então, os empregos obtidos por Sérgio fazem parte do aparato cultural do governo federal, como o Instituto Nacional do Livro (INL) e a Biblioteca Nacional. Passa a ser um daqueles intelectuais que, como chama a atenção Sérgio Miceli, encontrou guarida na ampliação das instituições culturais promovidas pelo Estado Novo (Miceli, 1979, p.131). O mundo aberto em que ele publicou Raízes do Brasil como um "lance" democrático tornou-se sombrio.

Como se não bastasse, em 1940, Sérgio é confrontado com o lançamento de Força, cultura e liberdade, de Almir de Andrade, professor de Direito da Universidade do Brasil que, no ano seguinte, ingressaria no Departamento de Imprensa e Propaganda (DIP), onde dirigiu a revista Cultura Política. Com esse livro, Almir de Andrade se tornava um dos ideólogos do Estado Novo, descrevendo o líder Getúlio Vargas e sua política como uma decorrência natural e adequada a um país que teria sido magistralmente descrito em Raízes do Brasil. Luiz Feldman realiza uma cuidadosa investigação em que revela como se deu essa transposição. Gostaria de grifar o caráter dramático que o contexto do Estado Novo e a publicação da obra de Almir trouxeram à vida de Sérgio. Trocando em miúdos, Almir de Andrade se apropria de Raízes do Brasil e busca traduzi-lo em um programa político. Realiza, a meu ver, uma dupla traição, não apenas ao seu conteúdo, como também à sua forma, relacionada a um modo democrático de se inscrever na arena pública. A suposição de Almir de Andrade de que o autor de Raízes poderia, do seu diagnóstico, ter extraído um programa político e que, por alguma falta - de vontade ou de coragem -, não o fez, obscureceu a atitude política de Sérgio: lançar um livro para que os cidadãos discutissem o seu devir.

Assim, se a recepção imediata da obra de Sérgio Buarque fez ressaltar a ausência de um fecho programático como uma falta de atitude política, Almir de Andrade dava um passo adiante e supunha ser possível preencher a lacuna. Essa apropriação é um indício para compreender o fato de Raízes do Brasil não ter tido nenhuma nova edição durante o Estado Novo, e nos faz entender melhor as direções dadas por Sérgio às suas principais modificações, que vêm à tona na segunda edição, publicada em 1948.

Este artigo não pretende, contudo, explorar essas mudanças. Se estiver correto enfatizar o caráter ensaístico de Raízes do Brasil, como peça de intervenção no espaço público, poderia sugerir que sua recepção se deu de forma 
inversa à que intencionava Sérgio. Seus leitores elogiaram a descrição do caráter nacional brasileiro, enquanto o autor propunha que eles - ao menos os das classes médias urbanas - se interrogassem e pusessem em questão a cordialidade como algo a ser superado com a urbanização. Complementarmente, de um lado, os leitores sentiram falta de um projeto político para a construção do Estado, de outro, o ensaísta sugeria que se deveria deixar de esperar a formulação de um aparato estatal advindo da mente dos statemakers. A forma do Estado brotaria da dinâmica social e do debate público.

\section{"Vencida Porém a escabrosidade da SERra do Mar..."}

Nesse contexto de fechamento do regime e quando o ambiente no Rio de Janeiro se torna sombrio, Sérgio Buarque começará a nutrir um projeto intelectual de estudo das bandeiras e das monções. Em março de 1939, com o título "Caminhos e Fronteiras", ele publica, na Revista do Brasil, seu primeiro texto sobre a temática, fruto, é provável, de pesquisas desenvolvidas na UDF. A partir de então passa a notar que "todo o sentido da história paulista prende-se por muito tempo aos caminhos, atalhos de pé posto ou estradas seguidas, sobretudo as vias de penetração criadoras de cidades e disciplinadoras do povoamento". Em "um mapa do século XVII", a profusão desses caminhos e cidades adentrando o interior contrasta com "os demais sítios povoados [que] não passam de simples manchas dispersas ao longe da marinha, mal plantados na terra e quase independentes dela. Situam-se em paragens melhor acomodadas à arribada de navios do que de bom acesso ao interior, como se sua existência estivesse exclusivamente voltada para o outro lado do Atlântico" (Holanda, 1939, p.14-15). ${ }^{3}$

Esse texto inaugura, no projeto intelectual de Sérgio Buarque de Holanda, bem entendido, a contraposição entre uma civilização sedentária e uma civilização nômade, em que

paisagens igualmente significativas, mas de colorido social bem diverso, contrapõem-se nos dois quadros. E se fosse possível distingui-las por um desses traços característicos, que valem por uma síntese, poderíamos dizer que, comparada à sociedade constituída no litoral e principalmente no litoral do Nordeste, nas terras do massapê - onde a riqueza agrícola procurava afinar os homens pelos gostos e até pelos requintes da Europa - essa que se forma no planalto da capitania de Martim Affonso encontra sua determinação antes no caminho, que convida ao 
movimento, do que no engenho de cana, que produz indivíduos sedentários. (Holanda, 1939, p.14, grifos nossos) ${ }^{4}$

Inicialmente, nesse projeto de estudo das bandeiras e da expansão dos colonizadores no planalto paulista, o indígena ocupa um papel absolutamente secundário, quase caricatural, "se entrou nesse conjunto, foi para trazer o elemento de desleixo, da facilidade e do lazer. Com ele aprende o conquistador o vício de fumar e de beber fumo, o processo primitivo das queimadas para a roça..." (Holanda, 1939, p.20).

Dois anos depois dessa publicação, Sérgio Buarque viaja aos Estados Unidos da América (EUA). Ligado ao Ministério da Educação e Saúde, pois era funcionário do INL, é convidado pelo Departamento de Estado norte-americano a permanecer naquele país por 3 meses. Desembarca em julho de 1941, em companhia do escritor Luis Jardim. É o tempo da política de boa vizinhança e do pan-americanismo de Roosevelt, durante a Segunda Guerra Mundial, quando os EUA descobrem que pouco conhecem seus vizinhos continentais. Multiplica-se, então, o número de bolsas de estudos, aumentando significativamente as possibilidades de intercâmbio de intelectuais. O americano Lewis Hanke - que Sérgio conhecera no Rio de Janeiro no ano anterior à sua viagem (Moraes, 1940) - como diretor da Fundação Hispânica da Biblioteca do Congresso, exercia importante papel na articulação das releituras da história do Continente, e a palavra de ordem era pensar a "história comum das Américas".

A tese da fronteira, de Frederick Jackson Turner, muito importante na historiografia norte-americana da época, foi bastante debatida entre os estudiosos do Novo Mundo, como se pudesse constituir uma chave interpretativa que aproximasse as diferentes experiências nacionais do Continente. Apresentada em 1893 nas comemorações dos 400 anos do descobrimento da América, constituía uma explicação que, concebida especificamente para os EUA, ao invés de salientar os valores puritanos e individualistas trazidos da Europa, enfatizava o que havia de novo no país, graças à sua dinâmica particular. Antes dela, de modo geral, predominava uma explicação segundo a qual os Estados Unidos teriam sido o resultado do estabelecimento de valores puritanos e individualistas em uma terra nova, sem passado feudal. A América era uma folha em branco a ser preenchida.

Opondo-se a tal concepção, Turner imprimiu uma dinâmica à nova terra e defendeu que a singularidade americana era fruto da fronteira. A terra livre teria exercido um papel de válvula de segurança para os conflitos sociais, permitindo que, à medida que as cidades e vilas saturassem, os indivíduos tivessem 
a oportunidade de partir para uma região não desbravada e, por seus próprios esforços, constituíssem uma nova sociedade. Esse processo criaria indivíduos igualitários, com iniciativa e amantes da liberdade. Dessa maneira, a democracia americana teria seu fundamento antes na dinâmica da fronteira que nos valores trazidos da Europa. De forma muito vivaz, Turner considera que, na fronteira, a natureza domina o adventício, fazendo que o europeu se obrigue a adotar maneiras e utensílios indígenas. Somente em um segundo momento, após a adaptação ao novo ambiente e ao nativo, o colonizador poderia rearticular seu legado anterior, adequando-o às novas condições de vida. Os valores europeus são, nesse processo, transformados. Daí a afirmação de Turner de que "a fronteira é a linha de mais rápida e efetiva americanização" (Turner, 1996, p.3-4).

Sérgio Buarque ficou sensibilizado com a reflexão acerca da história comum das Américas, como podemos depreender do artigo publicado no Jornal do Comércio, em 28 de setembro de 1941, no qual explicita a importância de sua estadia nos EUA. Em primeiro lugar, assume a crescente influência do país sobre o Continente e, em seguida, lembra que, entre os intelectuais, o Brasil é frequentemente pensado em oposição aos EUA. E afirma: "Na viagem de algumas semanas que acabo de realizar à América do Norte, acostumei-me a julgar melhor semelhante opinião" (Holanda, 1978, p.23).

Sérgio se alinha, dessa maneira, à preocupação compartilhada entre os historiadores das Américas. No caso, antes de ressaltar as diferenças entre o Brasil e os EUA, seria preciso analisar o que os países teriam em comum. As descrições, baseadas em oposições, eram quadros pintados com "traços grossos" e "cores vivas", que mais serviam para o descanso do intelecto do que para um efetivo equacionamento dos nossos dilemas e da nossa história. Então o articulista alerta para uma situação comum entre os dois países: a experiência da fronteira, tal como definida por Turner,

porque em nosso continente, não obstante todas as diversidades étnicas e culturais, existem de norte a sul feições sociais com raízes idênticas, geradas da aplicação de velhas instituições e velhas ideias a uma terra nova e livre. Nesse sentido pode-se mesmo dizer que, como o Oeste do historiador Frederick Jackson Turner, a América é antes uma forma de sociedade do que uma área geográfica. (Holanda, 1978, p.27)

O Novo Mundo deixa de ser uma folha em branco em que são impressos os valores transoceânicos, e passa a possuir "influências transformadoras" 
sobre os velhos valores. Não deixa de surpreender que, na mesma época, Sérgio Buarque publique também um pequeno artigo na Travel in Brazil, revista do DIP da Presidência da República, dirigida ao público estrangeiro. ${ }^{5}$ Em "Outlines of Brazilian History", após apontar para o papel fundamental do Estado Imperial na manutenção da unidade nacional, Sérgio indica o papel dos bandeirantes na expansão das nossas fronteiras a partir de uma lógica autônoma, independente do Estado e até apesar dele. Sobre esse segundo aspecto, contudo, Sérgio Buarque comenta que, ao contrário dos pioneiros, a expansão bandeirante foi descontínua e apenas excepcionalmente povoou a terra de maneira uniforme. Em suma, "um Jackson Turner brasileiro não seria capaz de escrever com facilidade um livro como The Frontier in American History" (Holanda, 1941, p.3). ${ }^{6}$

Quero crer que Sérgio Buarque de Holanda assumiu, desde então, a missão de ser "um Jackson Turner brasileiro" e, de fato, foi incapaz de escrever um volume coeso como The Frontier in American History. Sua obra se constitui de forma extensa e fragmentária. Apenas recentemente, com a publicação de Capítulos de Expansão Paulista, reunindo escritos dispersos, e da nova edição de Monções, com aparato crítico de Laura de Mello e Souza e de André Sekkel Cerqueira, passamos a ter melhor dimensão dela. Segundo a historiadora, a "estrela da vida inteira" de Sérgio foi a série de estudos e escritos "voltados para o passado paulista e para suas andanças pelo interior luso-americano" (Souza, 2014, p.18). Assim, podemos pensar Monções (1945), Caminhos e Fronteiras (1957), bem como os escritos reunidos em Capítulos de Expansão Paulista (2014) - sem imaginar os inúmeros "pequenos pedaços de papel escritos e reescritos à mão" (Souza, 2014, p.15), guardados no bolso e, provavelmente, perdidos - como uma imensa, porém fragmentária, obra sobre a expansão para o Oeste nas terras americanas que viriam a constituir o Brasil.

\section{FRONTEIRA}

Neste item, proponho realizar uma leitura dos primeiros textos de Sérgio Buarque à luz das rápidas considerações traçadas há pouco sobre a obra de Turner. Interessado em compreender o significado de seu projeto intelectual, no contexto em que foi gestado, atenho-me apenas aos textos publicados na década de $1940 .{ }^{7}$ O foco é o processo de adaptação dos adventícios às técnicas indígenas, para depois readquirirem seus conhecimentos trazidos do além-mar e do litoral. Detenho-me, para fins de exemplo, à construção e emprego de embarcações nas monções de comércio rumo a Cuiabá, expostas no livro 
Monções, de 1945. Diferentemente do texto de 1939, o indígena passa a ocupar papel central na expansão para o Oeste.

Muitos bandeirantes do século XVII vagaram em terras hoje mato-grossenses, mas o fizeram, sobretudo, a pé, e eventualmente em embarcações. Quando a travessia de um rio era inevitável, adequavam-se às técnicas indígenas de navegação e aprendiam a construir canoas com a casca do tronco das árvores. Essas canoas de confecção rápida, mas de pouca durabilidade, vinham ao encontro das necessidades daqueles que poderiam abandoná-las a qualquer momento para prosseguir sua marcha por terra, pois, "os gêneros que transportava uma dessas embarcações ... limitavam-se ao estrito necessário, já que os matos e rios constituíam, nesses casos, as principais estalagens do viajante, habituado a restringir sua dieta a frutos, raízes silvestres, répteis e ao que alcançasse com suas espingardas e anzóis" (Holanda, 1945, p.99).

Para os monçoeiros, as canoas feitas de casca de árvore não se mostraram adequadas às necessidades de prosseguir por via fluvial em longos percursos e levar uma carga que não se limitava às suas próprias necessidades, já que conduziam também mantimentos para comerciar com as novas cidades e arraiais que nasciam no extremo Oeste, em torno da extração de ouro e diamante. Isso não significa dizer que os monçoeiros abandonassem as técnicas indígenas. Na verdade, não só na construção, mas na própria maneira de conduzir a embarcação, eles se adaptaram às técnicas e aos recursos indígenas (Holanda, 1945, p.37).

Construídas a partir de um único tronco, as "pirogas” eram mais pesadas e de fabrico mais lento em comparação às canoas de casca, mas eram mais duráveis e resistentes e conduziam maior peso. Assim, adequaram-se melhor às necessidades de uma rota comercial que ia se consolidando na medida em que se estabeleciam povoados no extremo Oeste. Se as "pirogas" indígenas demonstraram desempenho satisfatório para o transporte das mercadorias, suportando seu peso e superando os muitos obstáculos das viagens, também apresentaram deficiências, o que exigiu um segundo passo para a rotinização do tráfego comercial. Foi preciso adaptar as embarcações para esse objetivo, e "os progressos nesse sentido teriam de ser, por força, morosos e orientados pela contínua experiência” (Holanda, 1945, p.98). Essa contínua experiência nem sempre foi fácil e sem consequências dolorosas. Os casos mais representativos e lamentáveis ocorreram nos primeiros anos de regularização da rota e demonstraram que apenas o recurso ao conhecimento indígena não se mostrava mais suficiente para as necessidades e dificuldades advindas da implantação de uma rota comercial. É importante notar que começa a 
despontar um novo passo do homem da fronteira, pois foi necessário lançar mão de recursos adventícios e adequá-los aos tomados do nativo. Nesse caso, depois de tristes experiências,

Tratou-se de remediar a falta, fazendo toldar as canoas, a exemplo do que acontecia nas embarcações fluviais do Velho Mundo. Usaram-se, com esse fim, cobertas de lona, brim ou baeta, sustentadas sobre uma armação de madeira, constituída de uma barra, que descansava sobre duas forquilhas, dispostas de um lado e outro da parte central da canoa, destinada à carga. Sobre a barra horizontal, a que chamavam cumieira, colocavam-se perpendicularmente, de palmo a palmo, barras menores, formando como um telhado, cujas extremidades ultrapassavam as bordas da canoa. (Holanda, 1945, p.100)

Portanto, foi necessário um recurso do Velho Mundo para se superar problemas que as novas experiências traziam e, aqui, o legado europeu começa a ser retomado, adequando-se, por assim dizer, à base formada inicialmente pela completa adaptação ao nativo. Nesse caso específico, o toldo, desconhecido entre os indígenas, passa a ser utilizado nas "pirogas" tomadas de empréstimo pelo europeu. Graças a esse recurso a rota comercial teve condições de se rotinizar e suprir as minas mato-grossenses de suprimentos. Segundo Sérgio Buarque, "a invenção, ou pelo menos, a difusão desse engenhoso sistema de abrigo, como o das canoas toldadas, que preservam os mantimentos, permitiu, com o decurso do século XVIII, que o comércio entre São Paulo e o Cuiabá se fizesse, aos poucos, sem grande parte das importunações e prejuízos que perseguiam as primeiras canoas" (Holanda, 1945, p.106).

Assim, estamos diante de um caso no qual os europeus e seus descendentes mobilizaram também os conhecimentos, recursos e técnicas do legado do Velho Mundo. Para atender às novas necessidades surgidas com o comércio, os monçoeiros acabaram por criar uma nova canoa, fruto desta vez de um amálgama de influências e tradições. Ou, sintetizando com as próprias palavras de Sérgio:

Intensificando-se a navegação dos rios do planalto, com o descobrimento das jazidas cuiabanas - o que só ocorre a partir do segundo decênio do século XVIII -, não se transformam no essencial as características herdadas da piroga indígena. A assiduidade nas vias fluviais, que conduzem ao sertão longínquo, a necessidade de transportar mercadorias e de resguardá-las durante as viagens, vão, aos poucos, fixando o perfil da canoa usada nas monções, sem no entanto alterar profundamente aquelas mesmas características. Assim é que, embora pouco su- 
periores às primitivas pirogas, sem quilha, sem leme, sem velas, essas canoas já comportam comodidades que denunciam algum progresso: remos à maneira de choupos de espontã, varas com juntas de ferro para subir os rios, cumieiras e cobertas de lona para proteger das chuvas. (Holanda, 1945, p.43-44)

Daí resulta, portanto, uma canoa indígena, coberta com toldo europeu, que, nesse raciocínio, é um produto novo, tipicamente americano. Com o risco do exagero, mas com a vantagem da força de uma imagem, é possível dizer que nessa canoa estão sintetizados os três momentos da fronteira: adaptação ao nativo, recuperação do legado europeu e amálgama de tradições que resulta em algo novo.

\section{MENTALIDADE CAPITALISTA}

Pensando a conexão entre as mudanças materiais e as dos indivíduos envolvidos no processo, vale notar que essa canoa serve também como metáfora das transformações nas mentalidades e valores. É como se, desde as andanças a pé e quase restritas à luta pela sobrevivência, até ao uso de canoas toldadas e estabelecimento de uma rota comercial, estivesse indicado o disciplinamento de um individualismo quase anárquico, em cujo desenrolar a ousadia começa a ceder lugar também à previdência e o ócio ao negócio. Para usar a expressão de Henrique Estrada Rodrigues, estaríamos diante de "certa utopia do comércio como veículo civilizacional” (Rodrigues, 2008, p.71). ${ }^{8}$

A partir do momento em que entra no sertão, o homem ibérico já não seria mais o mesmo. Diante de uma natureza mais forte que ele, foi obrigado a pagar um tributo, adaptando-se a ela e aos nativos da terra. E a sociedade que surge a partir desse processo de formação é nova, americana. $O$ disciplinamento não se dá por uma força externa que se impõe aos indivíduos, e a mudança ocorre gradualmente e sem revoluções. Segundo a imagem utilizada por Sérgio Buarque, "com a consistência do couro, não a do ferro ou do bronze, dobrando-se, ajustando-se, amoldando-se a todas as asperezas do meio" (Holanda, 1945, p.14). Ao apontar a diferença entre as mentalidades dos homens das monções e das bandeiras, Sérgio Buarque escreve que

os elementos de que agora dispõe o sertanista para alcançar sua terra de promissão vão deixar menor margem ao capricho e à iniciativa individuais. É inevitável pensar que o rio, que as longas jornadas fluviais tiveram uma ação disciplinadora e de algum modo amortecedora sobre o ânimo tradicionalmente aventuroso da- 
queles homens. A própria exiguidade das canoas das monções é um modo de organizar o tumulto, de estimular, senão a harmonia, ao menos a momentânea conformidade das aspirações em contraste. A ausência dos espaços ilimitados, que convidam ao movimento, o espetáculo incessante das densas florestas ciliares, que interceptam à vista o horizonte, a abdicação necessária das vontades particulares, onde a vida de todos está nas mãos de poucos ou de um só, tudo isso terá de influir poderosamente na mentalidade dos aventureiros, que demandam o sertão remoto. Se o quadro dessa gente aglomerada à popa de um barco tem, em sua aparência, qualquer coisa de desordenado não será a desordem das paixões em alvoroço, mas antes a de ambições submissas e resignadas. (Holanda, 1945, p.122)

No próprio intercâmbio com o mundo exterior, processa-se o ordenamento das paixões, de modo que podemos acompanhar o bandeirante, o monçoeiro, o tropeiro, o fazendeiro, o comerciante e o pequeno industrial se adequando lentamente, por conta de suas atividades cotidianas, às novas necessidades de um mundo em transformação. Podemos retomar essa "constelação" de figuras emblemáticas e observar a gradual mudança ocorrida no desenrolar desse processo em que, como escreve Sérgio Buarque em "Índios e mamelucos na expansão paulista”, de 1949, "o tropeiro é o sucessor direto do sertanista e o precursor, em muitos pontos, do grande fazendeiro. A transição faz-se assim sem violência” (Holanda, 1949, p.289).

Nessa transição, em meados do século XIX, "com as feiras de animais de Sorocaba, assinala-se distintamente uma significativa etapa na evolução da economia e também da sociedade paulista. Os grossos cabedais que nelas se apuram, tendem a suscitar uma nova mentalidade na população". Há, portanto, o surgimento dessa "nova mentalidade", resultante de um processo de transformação gradual e "sem violência", que culmina com a atividade tropeira, e por meio da qual "o espírito de aventura - que admite e quase exige a agressividade ou mesmo a fraude - encaminha-se, aos poucos para uma ação mais disciplinadora". Com isso, "à fascinação dos riscos e da ousadia turbulenta substitui-se o amor às iniciativas corajosas, mas que nem sempre dão imediato proveito. $\mathrm{O}$ amor da pecúnia sucede ao gosto da rapina”. Essas transformações fazem que se estabeleça entre os tropeiros - como, aliás, já começava a acontecer nas monções -, "uma ambição menos impaciente do que a do bandeirante", que "ensina a medir, a calcular oportunidades, a contar com danos e perdas. Em um empreendimento muitas vezes aleatório, faz-se 
necessária certa dose de previdência, virtude eminentemente burguesa e popular" (Holanda, 1949, p.289-290).

Em suma, podemos dizer que, por meio da dinâmica da expansão para o Oeste, forma-se uma mentalidade compatível com o moderno capitalismo, sem, contudo, um completo rompimento com valores e costumes associados normalmente a um mundo pré-burguês. Detecta-se uma mentalidade capitalista sem ascetismo racionalizante - o qual "parece inseparável do ideal burguês, ao menos em suas origens" (Holanda, 1949, p.290) -, e que, por isso mesmo, possibilita a vazão dos sentimentos e prazeres. Em síntese, à "americanização" no sentido geográfico correspondeu a "americanização” dos valores, no sentido desenvolvido na obra de Luiz Werneck Vianna, o "processo em que a América se desprende do que é singular à sua história, constituindo-se como expressão genérica do movimento expansivo da revolução da igualdade" (Werneck Vianna, 1997, p.117).

\section{UM Novo “LANCE” EM SÃo PAUlo}

Assim, cabe retornar às reflexões iniciais sobre a gênese desse projeto intelectual de Sérgio Buarque, gestado durante o Estado Novo e dedicado à sociedade paulista. Seu significado político aparece na conexão entre a história dos séculos XVII, XVIII e XIX e uma sociologia do século XX, sugerida nas próprias páginas de Monções (1945) e de "Índios e mamelucos na expansão paulista” (1949). Após lembrar os capítulos do deslocamento da fronteira até chegar às feiras de animais de Sorocaba, no século XIX, Sérgio Buarque lança a indagação: "Não haverá aqui, entre parêntese, uma das explicações possíveis para o fato de justamente São Paulo se ter adaptado, antes de outras regiões brasileiras, a certos padrões do moderno capitalismo?" (Holanda, 1949, p.290).

Passagem publicada em texto de 1949, precisamente no artigo "Índios e mamelucos na expansão paulista”, nos remete aos primeiros anos de pesquisa de Sérgio Buarque com o assunto e nos deixa próximos do fim do Estado Novo. Vamos lembrar que, exatamente em 1945, ele havia publicado Monções, o livro considerado um marco na sua trajetória, e, no ano seguinte, retornara a São Paulo para trabalhar no Museu Paulista, após mais de 25 anos no Rio de Janeiro. Como lembrou Laura de Mello e Souza, "mais de um estudioso indicou Monções como um divisor de águas entre o ensaísta e o historiador" (Souza, 2014, p.19). Essa conversão se deu por meio de uma intenção de compreender a sociedade formada a partir do planalto paulista e, se a obra histórica 
de Sérgio Buarque é muito mais ampla que isso, sua intenção inicial nunca foi abandonada, como revelou a mesma autora.

Em sua última entrevista, concedida a Richard Graham, Sérgio Buarque divaga: "em 1946, fui convidado para dirigir o Museu Paulista, cargo que ocupei por dez anos. Talvez a minha publicação de Monções, no ano anterior, tenha ajudado meu retorno espiritual, como o físico, a São Paulo" (Graham, 2009, p.200). Considerando que originalmente Monções tenha sido escrito para um concurso nos EUA, quando recebeu menção honrosa, Sérgio vinha trabalhando no livro havia tempos. Tanto que, em 15 de setembro de 1942, Mário de Andrade lhe escrevia fazendo um pedido um tanto insólito: "Concebi a ideia de ter os originais, projetos, rascunhos, etc. do livro que você está escrevendo pro tal concurso nos States, é possível?” (Monteiro, 2012, p.125-126). Nesse sentido, a mudança espiritual a que Sérgio Buarque se refere é anterior, e talvez possamos remetê-la àquele texto menor publicado em 1939, na Revista do Brasil, sob o título "Caminhos e Fronteiras". Ou, antes ainda, ao ano de 1937, quando o Rio de Janeiro deixou de ser a cidade aberta da prefeitura de Pedro Ernesto, da ampliação do ensino público e da UDF, e passou a ser a capital nebulosa do Estado Novo. Sérgio, então, trabalhava na Biblioteca Nacional e, lembraria mais tarde, "boatos circulavam constantemente nos cafés vizinhos, ou durante o almoço, no quarteirão seguinte, no prédio da Associação Brasileira de Imprensa" (Graham, 2009, p.199).

À mudança espiritual de cidade seguiu-se a física, já depois do fim do Estado Novo, em 1946. Se, com a publicação de Monções, no ano anterior, e na direção do Museu Paulista, Sérgio havia deixado de ser o ensaísta de Raízes do Brasil para ser um historiador, não significa que tenha deixado de atuar nos espaços públicos a partir da sua produção intelectual. Ao discutir Raízes do Brasil sugeri que o livro, e em especial o conceito de "homem cordial", era um "lance" jogado no espaço público, um mote para que os leitores refletissem e discutissem o que queriam fazer com aquilo que a história vinha fazendo dos brasileiros. A revolução silenciosa da urbanização, que Sérgio Buarque vinha vivenciando no Rio de Janeiro, era a hora das classes médias urbanas se haverem com sua identidade.

A obra aparentemente mais ascética do historiador, Monções, sem conceitos e tipos ideais - como aventura e trabalho, cordialidade e civilidade -, mas com a perquirição atenta das rotas de comércio fluvial, das curvas dos rios e da construção das embarcações, não significava a ausência de intervenção no espaço público e de intervenção na identidade de seus leitores. Ao menos é o 
que se pode depreender da conferência sobre as monções que proferiu no ano em que retornou à cidade e que concluiu com este chamado:

Um ... benefício ainda poderá ter ficado dessas audaciosas peregrinações ... Elas nos oferecem uma lição de prudente sabedoria. Lição para o presente e também para o futuro, mas que pertence igualmente à História, na parte em que a História é mestra da vida. O primeiro passo para a integração no mundo de nossa cultura de todo o imenso território, que constitui o coração deste continente sul-americano, nasceu da aventura e pode-se dizer que foi, todo ele, uma teimosa e magnífica aventura. Era inevitável que assim sucedesse. O que resta fazer, porém, para completar esse esforço, não poderá ser obra de aventura. Exigirá, provavelmente, o trabalho atento de algumas gerações de homens pacientes, metódicos e modestos. Nascerá das nossas legítimas necessidades e das nossas possibilidades efetivas, não de projetos espetaculares, bons apenas para a declamação e a lisonja. Significará uma luta penosa e de resultados talvez remotos, mas que há de ser realizado, porque somente com sua realização nos mostraremos verdadeiramente dignos do esplêndido legado das bandeiras e das monções. (Holanda, 1946, p.146) ${ }^{9}$

Um novo "lance" em uma nova cidade, e um novo projeto de país. Essa foi a resposta intelectual e política de Sérgio Buarque de Holanda ao Estado Novo.

\section{REFERÊNCIAS}

BARBOSA, Francisco de Assis. Verdes anos de Sérgio Buarque de Holanda: ensaio sobre sua formação intelectual até "Raízes do Brasil". In: Sérgio Buarque de Holanda: vida e obra. São Paulo: Secretaria de Estado da Cultura/Arquivo do Estado, Universidade de São Paulo/Instituto de Estudos Brasileiros, 1988. p.27-54.

CANDIDO, Antonio. Introdução. In: BARBOSA, Francisco de Assis (Org.) Raízes de Sérgio Buarque de Holanda. Rio de Janeiro: Rocco, 1988. p.119-129.

. Radicalismos. Estudos Avançados, São Paulo, IEA/USP, v.4, n.8, jan./abr. 1990.

DÁVILA, Jerry. Diploma de brancura: política social e racial no Brasil - 1917-1945. Trad. Claudia Sant'Ana Martins. São Paulo: Ed. Unesp, 2006.

EUGENIO, João Kennedy. Um horizonte de autenticidade. Sérgio Buarque de Holanda: monarquista, modernista, romântico (1920-1935). In: MONTEIRO, Pedro M.; EUGENIO, João Kennedy (Org.) Sérgio Buarque de Holanda: perspectivas. Campinas, SP: Ed. Unicamp; Rio de Janeiro: Ed. Uerj, 2008. p.425-459. 
FELDMAN, Luiz. Clássico por amadurecimento: estudos sobre Raizes do Brasil. Rio de Janeiro: Topbooks, 2016.

HOLANDA, Maria Amélia Buarque de. Apontamentos para a cronologia de Sérgio Buarque de Holanda (São Paulo, 1979). In: HOLANDA, Sérgio Buarque de. Raízes do Brasil. Org. Ricardo Benzaquen de Araújo; Lilia Moritz Schwarcz. ed. rev. São Paulo: Companhia das Letras, 2006. p.421-446.

HOLANDA, Sérgio Buarque de. As monções. In: TAUNAY, Affonso de E.; ELLIS JUNIOR, Alfredo et al. Curso de bandeirologia. São Paulo: Departamento Estadual de Informações, 1946. p.126-146.

. Caminhos e fronteiras. Revista do Brasil, Rio de Janeiro, ano II, n.9, p.14-20, mar. 1939.

. Considerações sobre o americanismo. In: Cobra de vidro. 2.ed. São

Paulo: Perspectiva; Secretaria da Cultura Ciência e Tecnologia do Estado de São Paulo, 1978.

. Dr. Júlio Prestes: o futuro presidente da República dos Estados Unidos do Brasil. In: . Sérgio Buarque de Holanda: escritos coligidos - Livro I, 19201949. Org. Marcos Costa. São Paulo: Ed. Unesp; Fundação Perseu Abramo, 2011. p.40-42.

. Índios e mamelucos na expansão paulista. Anais do Museu Paulista, São Paulo, Separata do v.13, p.177-290, 1949. . Monções. Rio de Janeiro: Casa do Estudante do Brasil, 1945. . Outlines of Brazilian History. Travel in Brazil, v.I, n.I, p.2-3, 1941. . Tentativas de Mitologia. São Paulo: Perspectiva, 1979.

LEÃO, Múcio. Carta a Rui Ribeiro Couto. Rio de Janeiro, 22 maio 1931. Fundação Casa de Rui Barbosa, Fundo Rui Ribeiro Couto, Correspondência Passiva.

MICELI, Sergio. Intelectuais e classe dirigente no Brasil (1920-1945). São Paulo: Difel, 1979.

MONTEIRO, Pedro M. A queda do aventureiro: aventura, cordialidade e os novos tempos em Raizes do Brasil. Campinas, SP: Ed. Unicamp, 1999.

. (Org.) Mário de Andrade e Sérgio Buarque de Holanda: Correspondência. São Paulo: Companhia das Letras; Instituto de Estudos Brasileiros; Edusp, 2012.

MORAES, Rubens B. de. Carta a Sérgio Buarque de Holanda, São Paulo, 24 jun. 1940. SIARQ/UNICAMP - Fundo Privado Sérgio Buarque de Holanda; SBH/Cp (Série: Correspondência; Sub-série: Passiva).

MOTTA, Marly S. da. O Rio de Janeiro: de cidade-capital a Estado da Guanabara. Rio de Janeiro: Ed. FGV, 2001.

POCOCK, J. G. A. Linguagens do ideário político. Trad. Fábio Fernandez. São Paulo: Edusp, 2003. 
RODRIGUES, Henrique E. Os sertões incultos e o ouro do passado. In: MONTEIRO, Pedro M.; EUGENIO, João Kennedy (Org.) Sérgio Buarque de Holanda: perspectivas. Campinas, SP: Ed. Unicamp; Rio de Janeiro: Ed. Uerj, 2008. p.63-82.

SKINNER, Quentin. Meaning and Understanding in the History of Ideas. History and Theory, v.8, n.1, p.3-53, 1969.

SOUZA, Laura de Mello e. Prefácio: Estrela da vida inteira. In: HOLANDA, Sérgio Buarque de. Monções e Capítulos de expansão paulista. 4.ed. Org. Laura de Mello e Souza, André Sekkel Cerqueira. São Paulo: Companhia das Letras, 2014. p.15-37.

TURNER, Frederick J. The frontier in American history. 3.ed. New York: Dover, 1996. WAIZBORT, Leopoldo. O mal-entendido da democracia: Sergio Buarque de Hollanda, Raizes do Brasil, 1936. Revista Brasileira de Ciências Sociais. v.26, n.76, p.39-62, jun. 2011.

WEGNER, Robert. A conquista do Oeste: a fronteira na obra de Sérgio Buarque de Holanda. Belo Horizonte: Ed. UFMG, 2000.

WERNECK VIANNA, Luiz. A revolução passiva: iberismo e americanismo no Brasil. Rio de Janeiro: Revan, 1997.

\section{NOTAS}

${ }^{1}$ Doutor em Sociologia (Instituto Universitário de Pesquisas do Rio de Janeiro/Iuperj, 1999). Pesquisador da Casa de Oswaldo Cruz, Docente do Programa de Pós-Graduação em História das Ciências e da Saúde/Fiocruz e Professor do Quadro Complementar do Departamento de Ciências Sociais da PUC-Rio.

${ }^{2}$ Sobre a simpatia monarquista do jovem Sérgio, ver Eugenio (2008).

${ }^{3}$ Como Sérgio resumiu posteriormente, procurou escrever "uma espécie de Casa-grande e senzala ao avesso". Enquanto "esse livro do Freyre faz o Brasil parecer estático; dominado pelo açúcar; olhando para o Atlântico; parado. Eu queria algo mais dinâmico, apontando para as Minas, para o interior. Brasil em movimento" (GRAHAM, 2009, p.205).

${ }^{4}$ Em comunicação pessoal, Élide Rugai Bastos sugeriu a ligação desse projeto de Sérgio Buarque com a obra do escritor árabe do século XIV Ibn Khaldun (1332-1406), Os prolegômenos ou filosofia social, onde desenvolve a oposição entre povos nômades e sedentários. A edição brasileira em três volumes é de 1958 e Sérgio Buarque a possuía. É possível que já conhecesse anteriormente a obra. Agradeço a Élide Rugai Bastos o incentivo para a produção deste artigo.

${ }^{5}$ Salvo engano, esse artigo era desconhecido até recentemente e veio à luz por obra de Luiz Feldman, que se refere a ele em Clássico por amadurecimento. Ver suas considerações sobre o texto (FELDMAN, 2016, p.208ss). Agradeço a Luiz Feldman a cópia do texto da Travel in Brazil e os diálogos que inspiraram este artigo. 
${ }^{6} \mathrm{~A}$ passagem no original: "If we let ourselves be led by appearances, the expansionist efforts of the 'bandeirantes' may be compared to the struggles of the American squatters in their slow and constant march towards the West. This appearance, however, is deceitful, as the 'bandeirantes' expansion was many times discontinued, and they only settled definitely on the outskirts of the wilderness when mines were discovered. Although their efforts were prodigious, only exceptionally were they directed towards peopling the land. A Brazilian Jackson Turner would not be able to easily write a book such as The Frontier in American History" (Holanda, 1941, p.3).

${ }^{7}$ Assim, todas as citações provêm do livro Monções (1945), da conferência com o mesmo nome publicada no ano seguinte e de "Índios e mamelucos na expansão paulista" (1949). Para uma discussão sobre o tema tratado nos dois próximos tópicos, ver Wegner (2000) e Rodrigues (2008).

${ }^{8} \mathrm{O}$ texto de Henrique Estrada Rodrigues é pessimista quanto à referida "utopia" e enfatiza a interferência dos governadores nas monções e na expansão para Oeste.

${ }^{9}$ Anos mais tarde essa conferência se tornaria exatamente um capítulo do livro Caminhos e fronteiras, publicado em 1957, exceto pela exclusão desses dois parágrafos com que o autor concluiu sua conferência.

Artigo recebido em 11 de julho de 2016. Aprovado em 26 de agosto de 2016. 